\title{
Factors Associated with Health-Related Quality of Life in Multiple Sclerosis
}

\author{
Wilma M. Hopman, Helen Coo, Cathy M. Edgar, Evelyn V. McBride, \\ Andrew G. Day, Donald G. Brunet
}

\begin{abstract}
Background: Much research has gone into the assessment of function and health-related quality of life (HRQOL) in those with multiple sclerosis (MS). The Medical Outcomes Study 36-item short form (SF-36) has been widely used in this population but current recommendations are that it be supplemented with condition-specific measures such as the MS Quality of Life Inventory (MSQLI) and the MS Functional Composite (MSFC). The goal of the baseline component of this study was the measurement of generic and condition-specific HRQOL, and the identification of factors associated with these outcomes. Methods: HRQOL was assessed at the baseline phase of a longitudinal study. Participants completed the assessment during their regularly scheduled clinic visit. Results: 300 of 387 eligible patients agreed to participate, for a response rate of $77.5 \%$. Age ranged from 22 to 77 years, while duration of MS ranged from 1 to 47 years. Mean SF-36 scores were well below age- and sex-adjusted normative data. Only 240 completed the MSFC component. Higher EDSS, use of support services, pain medications, clinical depression and antidepressant use were associated with poorer HRQOL, while higher income and education were associated with better HRQOL. Conclusions: There is a substantial burden of illness associated with MS when compared to normative HRQOL data. This was more pronounced in physically- than in mentallyoriented domains. Assessment of HRQOL provides a valuable complement to the EDSS by providing information about the patient perception of function and HRQOL beyond that which can be obtained by physical assessment alone.
\end{abstract}

RÉSUMÉ: Facteurs associés à la qualité de vie reliée à la santé dans la sclérose en plaques. Contexte : L'évaluation du fonctionnement et de la qualité de vie reliée à la santé (QVRS) chez les patients atteints de sclérose en plaques (SEP) a fait l'objet de beaucoup de recherches. Le Medical Outcomes Study 36-item short form (SF-36) a été très utilisé chez ces patients. Cependant, on recommande maintenant d'y ajouter des mesures spécifiques à la maladie comme le MS Quality of Life Inventory (MSQLI) et le MS Functional Composite (MSFC). Le but du volet initial de cette étude était de mesurer la QVRS générique et spécifique à la maladie et d'identifier les facteurs associés à ses répercussions. Méthodes : La QVRS a été évaluée lors de la phase initiale d'une étude longitudinale. Les participants complétaient l'évaluation pendant leur visite de suivi régulier à la clinique. Résultats : 300 des 387 patients éligibles ont accepté de participer, soit un taux de participation de 77,5\%. Ils étaient âgés de 22 à 77 ans et atteints de la maladie depuis 1 à 47 ans. Les scores SF-36 moyens étaient bien en deçà des données normatives ajustées pour l'âge et le sexe. Seulement 240 patients ont complété la composante MSFC. Un score EDSS plus élevé, l'utilisation de services de soutien, une médication anti-douleur, la dépression clinique et l'utilisation d'antidépresseurs étaient associés à une moins bonne QVRS. Un revenu et un niveau de scolarité plus élevés étaient associés à une meilleure QVRS. Conclusions : Il existe un fardeau dû à la maladie qui est substantiel chez les patients atteints de la SEP par rapport aux données normatives sur la QVRS. Ce fardeau était plus lourd dans les domaines axés sur le fonctionnement physique que sur le fonctionnement mental. L'évaluation de la QVRS est un complément précieux au EDSS en fournissant de l'information sur la perception qu'a le patient de son état fonctionnel et de sa QVRS, au-delà de ce qui peut être obtenu par l'évaluation physique seule.

Can. J. Neurol. Sci. 2007; 34: 160-166

Multiple sclerosis (MS) is a chronic disease of the central nervous system with an average onset at 30 years of age and a lifetime cost estimated at approximately 1.6 million Canadian dollars per person. ${ }^{1}$ Additional data suggest that costs rise with increasing level of disability, ${ }^{2}$ and with relapses and inability to work. $^{3}$

Since MS is a chronic condition without a cure, a considerable amount of research has gone into the assessment of function and health-related quality of life (HRQOL) in this population. ${ }^{3-7}$ The Expanded Disability Status Scale (EDSS) ${ }^{8}$ is widely used to quantify disability and neurological impairment, but the evidence suggests that with the exception of physical function, the EDSS correlates poorly with the multiple

From the Clinical Research Centre (WMH, AGD), Multiple Sclerosis Clinic (CME, EVM, DGB), Kingston General Hospital; Department of Community Health and Epidermiology (WMH, HC, AGD), Department of Medicine (DGB), Division of Neurology, Queen's University, Kingston, Ontario, Canada.

ReCEIVED SEPTEMber 12, 2006. ACCEPTED IN FinAl FORM February 9, 2007. Reprint requests to: Wilma M. Hopman, Clinical Research Centre, Kingston General Hospital, Angada 4, Room 5-426, Kingston, Ontario, Canada, K7L 2 V7. 
dimensions of HRQOL, such as mental health, social functioning, vitality, pain and general health. ${ }^{5,7,9}$

One of the most commonly used measures of HRQOL in this population is the Medical Outcomes Study Short-Form 36 (SF36). ${ }^{10,11}$ It consists of 36 items encompassing 8 HRQOL domains including Physical Function, Role Physical, Bodily Pain, General Health, Vitality, Social Functioning, Role Emotional and Mental Health. Domains are scored on standardized scales from $0-100$, with higher values representing better HRQOL. ${ }^{10}$ Two summary scores, a Physical Component Summary (PCS) and a Mental Component Summary (MCS), are standardized to a mean of 50, with a score above 50 representing better than average function and below 50 poorer than average function. ${ }^{11}$ The SF-36 can effectively discriminate between people with different chronic conditions ${ }^{12,13}$ and can detect significant treatment effects in various populations. ${ }^{13}$

Although it has been widely used in the MS population, ${ }^{3-}$ $7,9,14,15$ the SF-36 may not be sufficiently sensitive to HRQOL changes in MS-specific symptoms, such as fatigue, visual impairment and bowel and bladder control. ${ }^{4,15}$ Therefore it has been recommended that the SF-36 be supplemented with condition-specific measures of HRQOL to assess these symptoms. ${ }^{4,13,16}$ The MS Quality of Life Inventory (MSQLI) ${ }^{13}$ was developed by a panel of MS experts, persons with MS, and caregivers. The short form contains 81 items, including the entire SF-36 and additional items for measuring fatigue, pain, sexual satisfaction, bladder control, bowel control, visual impairment, cognitive function (using the Perceived Deficits Questionnaire or $\mathrm{PDQ}^{17}$ ) and social support. ${ }^{13}$ In addition, the National Multiple Sclerosis Society's Clinical Outcomes Assessment Task Force has recommended the inclusion of the Multiple Sclerosis Functional Composite (MSFC) as a clinical outcome in MS patients. ${ }^{16,17}$ The MSFC consists of a timed 25-foot walk, 9-hole peg test and paced auditory serial addition test (PASAT), and takes about 20 minutes to complete. ${ }^{18}$

This study builds on a pilot study that assessed correlates of HRQOL in a sample of 100 patients. ${ }^{5}$ However, in addition to the SF-36, correlates of the eight additional domains of the MSQLI, the EDSS and the MSFC were also assessed in this larger sample. Much of the previous work assessing HRQOL in this population has examined the impact of specific interventions in a pre/post design, or restricted the assessment of changes in HRQOL to persons with a specific clinical course of MS in the context of clinical trials of drug therapies. This study utilized an observational design, which has the advantage over randomized controlled trials in that a broader range of independent variables can be studied. The study population is not limited to those meeting the often rigid inclusion criteria for clinical trials, but includes those on a variety of treatments and interventions. For the same reason, the results of observational studies tend to be more generalizable to the general population of those with MS.

The objectives of this study included: 1) the assessment of HRQOL at baseline, and the identification of factors associated with HRQOL at baseline; 2) the assessment of change over two years, along with the identification of factors associated with change; and 3) the clinical relevance of the changes. The results for Objective 1 are presented in this manuscript; two subsequent manuscripts will focus on the remaining two objectives.

\section{MeTHODS}

A detailed description of the methodology is available elsewhere, ${ }^{19}$ but in brief, all individuals with an appointment at the MS Clinic of Kingston General Hospital in Kingston, Ontario between September 2000 and August 2001 were invited to participate in the baseline component of this longitudinal study of HRQOL. Eligibility criteria included clinically definite MS, a diagnosis of at least 12 months duration (for HRQOL to stabilize following diagnosis), no severe cognitive impairment (impairment defined as Mini-Mental State Exam < 24) and ability to communicate verbally. The clinic neurologist determined disease course (progressive [primary, secondary,

Table 1: Sample characterististics at Baseline, $n=300 *$

\begin{tabular}{|c|c|}
\hline Characteristics, Linear Data & Mean (SD) \\
\hline Age (years) & $46.7(10.5)$ \\
\hline Duration of MS (years) & $14.4(9.8)$ \\
\hline Characteristics, Categorical data & $\mathbf{N}(\%)$ \\
\hline Male & $77(25.7)$ \\
\hline Live alone & $40(13.3)$ \\
\hline \multicolumn{2}{|l|}{ Clinical course } \\
\hline Primary progressive & $19(63)$ \\
\hline Secondary progressive & $101(33.7)$ \\
\hline Progressive relapsing & $11(3.7)$ \\
\hline Relapsing remitting & $169(56.3)$ \\
\hline \multicolumn{2}{|l|}{ Education } \\
\hline$\leq$ Some high school & $49(16.4)$ \\
\hline Completed high school & $58(19.3)$ \\
\hline Post-secondary & $187(62.3)$ \\
\hline \multicolumn{2}{|l|}{ Household income } \\
\hline$\leq \$ 20,000$ & $62(20.7)$ \\
\hline$\$ 20-39,999$ & $78(26.0)$ \\
\hline$\$ 40-59,999$ & $52(17.3)$ \\
\hline$\geq \$ 60,000$ & $79(26.3)$ \\
\hline Relapse in past year & $46(15.3)$ \\
\hline \multicolumn{2}{|l|}{ Employment status } \\
\hline Unemployed & $28(9.3)$ \\
\hline Disability & $140(46.7)$ \\
\hline Employed full time & $58(19.3)$ \\
\hline Retired & $24(8.0)$ \\
\hline Other (part time, student, etc.) & $37(12.3)$ \\
\hline \multicolumn{2}{|l|}{ EDSS category } \\
\hline Mild (0-3) & $138(46.0)$ \\
\hline Moderate (3.5-6.5) & $137(45.7)$ \\
\hline Severe $(>6.5)$ & $24(8.0)$ \\
\hline
\end{tabular}


progressive-relapsing] or relapsing-remitting) and assigned the EDSS. Ethics approval for the study was obtained from the Queen's University and Affiliated Teaching Hospitals Research Ethics Board.

Two weeks prior to their scheduled clinic visit, all eligible participants received a package containing an information letter, a consent form and the MSQLI. Consenting patients returned the completed questionnaires during the clinic visit. In addition, the MSFC was administered at this time, including the timed 25-foot walk, the nine-hole peg test and the PASAT. The administration of the MSFC followed procedures outlined in the manual. ${ }^{20}$ Additional information to be collected was identified on the basis of previous work, a comprehensive literature review and input from clinicians. Chart review was utilized to obtain clinical characteristics such as type of MS, EDSS, interventions (use of aids, medications), clinical course, and descriptors of the patients' condition, such as incontinence and number of relapses in previous year. Additional information was obtained via patient questionnaire (e.g. education level, marital status, smoking status, family history, use of services such as physiotherapy, visiting nurses and home making services, and comorbid conditions).

Data were entered into SPSS (Version 12.0 for Windows, Chicago, Illinois, 2004) for scoring and analysis. Scoring of the MSQLI and the MSFC was done as per the instructions in the manuals. ${ }^{13,19}$ The test results from the MSFC baseline data for participants were used as the reference population for creating the MSFC $\mathrm{z}$-scores, as recommended by the developers. ${ }^{19}$ Data were described using univariate statistics, and bivariate associations between the various sociodemographic and clinical characteristics and the 20 outcome measures (8 SF-36 domain and 2 summary scores, EDSS, MSFC, and an additional 8 subscales from the MSQLI), were assessed by means of t-tests, analysis of variance and correlation. Variables with a bivariate association of $\mathrm{p}<0.15$ were offered into multivariable linear regression models of the 20 outcomes using a stepwise approach.

\section{Results}

Of 387 eligible individuals, 300 agreed to participate, 63 refused and 24 did not come to their appointment, for a response rate of $77.5 \%$. Several key characteristics of the respondents and the non-respondents were compared to see if the respondents could be considered representative of the larger population. There were no significant differences between respondents and nonrespondents in terms of gender $(74.3 \%$ versus $67.8 \%$ female respectively, $\mathrm{p}=0.27)$ or clinical course $(43.7 \%$ versus $45.6 \%$ progressive respectively, $\mathrm{p}=0.28$ ). The mean EDSS score of the respondents $(3.8 \pm 2.1)$ was similar to that of the non-respondents $(4.0 \pm 2.2), p=0.54$, and the median EDSS score was 3.5 for both groups. The mean age of the two groups was also similar ( $46.7 \pm$ 10.5 for the respondents, $47.3 \pm 10.5$ for the non-respondents, $\mathrm{p}=0.68)$.

Table 1 describes the characteristics of the sample. Due to the low frequency in two subgroups, the three progressive groups were collapsed for analysis $(n=131$, or $43.7 \%)$. Age ranged from 22 to 77 years, while duration of MS ranged from one to 47 years.

Table 2 describes the clinical characteristics and interventions that were utilized in the regression analyses. Several additional living circumstances variables (e.g. pregnancy, dependent children), comorbidities (heart disease, diabetes) and support services (speech therapy) were collected, but the frequencies were too low to be used in the analyses. A positive family history was reported for $80(26.7 \%)$ individuals, while an additional 15 $(5 \%)$ indicated that they did not know. Since the frequency of this latter sub-group was too small for separate analysis, these were combined with those who indicated that they did not have a family history.

Table 3 contains the MSQLI domain scores, the EDSS and the MSFC, as well as the age- and sex-adjusted normative data for the SF-36 domains and component summaries. ${ }^{21}$ The possible ranges are also provided, as these vary between scales. For 12 of the scales, positive values represent better function, while for the 8 marked with an asterisk, higher scores represent poorer function. The Sexual Satisfaction Scale is only appropriate for those with a relationship with one primary partner, and 214/300 $(71.3 \%)$ provided a response to this scale. The MSFC was completed by $245(81.7 \%)$, as $16(5.3 \%)$ were too fatigued or

Table 2: Clinical characteristics and interventions at baseline, $n=300 *$

\begin{tabular}{|c|c|}
\hline Clinical Characteristic/Intervention & $\mathbf{N}(\%)$ \\
\hline Family history & $80(26.7)$ \\
\hline No or occasional incontinence & $217(72.4)$ \\
\hline Frequently or always incontinent & $28(9.3)$ \\
\hline Intermittent catheterization & $16(5.3)$ \\
\hline No aids needed & $170(56.7)$ \\
\hline Uses cane & $50(16.7)$ \\
\hline Uses walker & $41(13.7)$ \\
\hline Uses wheelchair & $39(13.0)$ \\
\hline Still driving an automobile & $238(79.3)$ \\
\hline Medication for pain & $53(17.7)$ \\
\hline Antispasticity medication & $71(23.7)$ \\
\hline Medication for fatigue & $23(7.7)$ \\
\hline Use of antidepressants & $30(10.0)$ \\
\hline Currently smoking & $89(29.7)$ \\
\hline Uses Copaxone & $40(13.3)$ \\
\hline Uses Avonex & $16(5.3)$ \\
\hline Uses Betaseron & $36(12.0)$ \\
\hline Uses Rebif & $25(8.3)$ \\
\hline Sleep disorder & $26(8.7)$ \\
\hline Migraines & $68(22.7)$ \\
\hline High blood pressure & $45(15.0)$ \\
\hline Clinical depression (past or current) & $55(18.3)$ \\
\hline Caregiver (informal) & $149(49.7)$ \\
\hline Use of Allied Health (PT, OT, social work) & $151(50.3)$ \\
\hline Dietician & $29(9.7)$ \\
\hline Urology & $61(20.3)$ \\
\hline Counselling & $50(16.7)$ \\
\hline Visiting nurse & $75(25.0)$ \\
\hline Homemaker services & $77(25.7)$ \\
\hline Support group & $64(21.3)$ \\
\hline Naturopath, osteopath, etc. & $45(15.0)$ \\
\hline
\end{tabular}

*Numbers do not always total 300 due to missing data 
Table 3: MSQLI scores, and age-and sex-adjusted normative data for the SF-36

\begin{tabular}{|c|c|c|c|}
\hline Domain and Possible Ranges of Scores & $\mathbf{N}$ & $\begin{array}{c}\text { Baseline Scores } \\
\text { Mean (SD) }\end{array}$ & $\begin{array}{c}\text { Age- and Sex-adjusted } \\
\text { Normative Data } \\
\text { Mean }(\mathrm{SD})^{* *}\end{array}$ \\
\hline SF-36 Physical Function (0-100) & 289 & $40.5(30.2)$ & $86.9(16.9)$ \\
\hline SF-36 Role Physical (0-100) & 287 & $24.0(36.8)$ & $82.0(33.0)$ \\
\hline SF-36 Bodily Pain (0-100) & 294 & $59.5(27.2)$ & $74.8(23.0)$ \\
\hline SF-36 General Health $(0-100)$ & 294 & $51.7(24.1)$ & $77.1(17.9)$ \\
\hline SF-36 Vitality $(0-100)$ & 294 & $35.1(21.7)$ & $64.9(17.9)$ \\
\hline SF-36 Social Function $(0-100)$ & 295 & $57.3(27.6)$ & $85.4(19.7)$ \\
\hline SF-36 Role Emotional (0-100) & 283 & $56.1(44.9)$ & $83.7(31.5)$ \\
\hline SF-36 Mental Health $(0-100)$ & 294 & $67.1(20.8)$ & $76.9(15.3)$ \\
\hline SF-36 Physical Component Summary (8-73) & 279 & $33.6(10.6)$ & $50.7(8.7)$ \\
\hline SF-36 Mental Component Summary (10-74) & 279 & $46.0(12.2)$ & $51.3(9.1)$ \\
\hline Expanded Disability Status Scale $(0-10) *$ & 299 & $3.8(2.1)$ & - \\
\hline Modified Fatigue Impact Scale $(0-20) *$ & 289 & $12.3(4.7)$ & - \\
\hline Pain Effects Scale (6-30)* & 282 & $15.1(6.3)$ & - \\
\hline Sexual Satisfaction Scale (4-24) * & 214 & $11.5(6.3)$ & - \\
\hline Bladder Control Scale $(0-22) *$ & 279 & $5.4(6.0)$ & - \\
\hline Bowel Control Scale $(0-26) *$ & 287 & $4.0(4.6)$ & - \\
\hline Impact of Visual Impairment Scale $(0-15) *$ & 295 & $2.0(2.8)$ & - \\
\hline Perceived Deficits Questionnaire $(0-20) *$ & 295 & $7.4(5.0)$ & - \\
\hline Social Support Survey Transformed (0-100) & 293 & $75.7(22.8)$ & - \\
\hline MS Functional Composite (z-score) & 240 & $0.036(0.77)$ & - \\
\hline
\end{tabular}

* Higher scores represent poorer function. ** Normative data are only available for the SF-36. All differences between the sample and the normative data were highly significant at $\mathrm{p}<0.001$, one-sample t-test.

Table 4: Summary of Linear Regression Models for SF-36 Component of the MSQLI

\begin{tabular}{|c|c|c|c|c|c|c|c|c|c|c|}
\hline Variable & PF & $\mathrm{RP}$ & $\mathrm{BP}$ & $\mathrm{GH}$ & VT & SF & $\mathrm{RE}$ & MH & PCS & MCS \\
\hline Constant & 116.2 & 23.1 & 99.4 & 111.1 & 77.1 & 115.0 & 93.3 & 72.2 & 58.8 & 56.3 \\
\hline Age & -0.5 & & & & & & & 0.3 & -0.2 & \\
\hline Clinical course & & 13.0 & & & & & & & & \\
\hline Education & & 7.7 & 6.0 & & & 7.4 & 8.8 & & & \\
\hline Income & 3.8 & & & & & & 10.1 & 4.3 & & 2.7 \\
\hline EDSS category (1-3) & -16.1 & & & & & & & & & \\
\hline Unemployed & & & & -14.5 & & & & & & \\
\hline On disability & & & & -14.1 & & & & & & \\
\hline Currently smoking & & & & & & & & & & -3.9 \\
\hline Intermittent catheterization & & & & & & & -29.2 & & & \\
\hline Use of aids (1-4) & -5.3 & & & & & & & & -2.4 & \\
\hline Medication for pain & & & & -8.4 & & -8.2 & & & -4.7 & \\
\hline Migraines & & & & -6.5 & -11.9 & & & & & \\
\hline High blood pressure & & & & & & & -15.9 & & & \\
\hline Clinical depression & & & -12.8 & & -11.8 & -19.8 & -29.1 & -14.7 & & -10.1 \\
\hline Caregiver & -10.3 & -9.4 & -11.1 & & -8.1 & & & & & \\
\hline Use of Allied Health & -6.9 & -16.3 & -8.2 & & & -9.7 & & & & \\
\hline Urology & & & & & & & & & -3.8 & \\
\hline Counselling & & & & & & & & -8.6 & & \\
\hline Visiting nurse & & & & -11.1 & & -13.1 & & & & \\
\hline Naturopath, osteopath, etc. & & & -8.5 & & & -9.2 & & & & \\
\hline F-statistic & 51.3 & 16.2 & 12.5 & 14.1 & 13.0 & 16.9 & 15.6 & 21.0 & 19.6 & 26.5 \\
\hline p-value of model & $<0.001$ & $<0.001$ & $<0.001$ & $<0.001$ & $<0.001$ & $<0.001$ & $<0.001$ & $<0.001$ & $<0.001$ & $<0.001$ \\
\hline Adjusted R-square & 0.54 & 0.18 & 0.17 & 0.24 & 0.14 & 0.26 & 0.23 & 0.24 & 0.24 & 0.24 \\
\hline
\end{tabular}

For dichotomous variables, no=1, yes $=2$. For clinical course, $1=$ progressive, $2=$ relapsing. All variables listed were statistically significant $(\mathrm{p}<0.05$ minimum) PF = Physical Function, RP = Role Physical, BP = Bodily Pain, GH = General Health, VT = Vitality, SF = Social Function, RE = Role Emotional, $\mathrm{MH}=$ Mental Health, $\mathrm{PCS}=$ Physical Component Summary, MCS = Mental Component Summary 
were missed at the clinic when study staff were with other participants, $15(5.0 \%)$ refused to do the PASAT and $24(8.0 \%)$ started but refused to complete the PASAT.

Tables 4 (SF-36) and 5 (EDSS, remaining domains of MSQLI other than SF-36, MSFC) contain the results of the regression models for the 20 outcomes. For the SF-36 outcomes, all models were highly significant, and the variation in outcome accounted for by the models ranged from 14\% (Vitality) to 54\% (Physical function). Use of services such as informal caregivers, allied health, urology, counselling, visiting nurses and naturopath/other alternative or complementary practitioner was consistently associated with poorer HRQOL. Clinical depression was associated with poorer HRQOL in five models (pain, vitality, social function, role emotional and mental health) as well as the MCS. Income and education, however, were associated with higher HRQOL in four models (physical function, role emotional, mental health and the MCS for income; role physical, pain, social function and role emotional for education). Age was associated with poorer HRQOL in two physically oriented models (physical function and the PCS) and with better mental health. Use of medication for pain was associated with poorer HRQOL in three models (general health perception, social function and the PCS); the remaining variables, including EDSS category, were represented two or less times in the models.

In Table 5, higher scores represent poorer function for the EDSS and seven of eight MSQLI outcomes, while the remaining two (MSQLI Social Support and the MSFC) are similar to the SF-36 in that higher scores represent better function. All models were highly significant, accounting for between 10\% (Sexual Satisfaction) to $71 \%$ (EDSS) of the variation in outcome. However, the $\mathrm{R}^{2}$ for the model of EDSS was likely artificially high, as the use of aids was a predictor and this largely defines the scoring in the EDSS. For the nine outcomes other than EDSS, the assigned value of EDSS was used as an independent variable, as this consistently proved to be more strongly associated with the outcomes than the EDSS category. EDSS was significantly negatively associated with outcomes in five models (fatigue, pain, sexual function, bladder function and the MSFC). Use of support services was again associated with poorer HRQOL, as was clinical depression (4 models including fatigue, pain, the

Table 5: Summary of Linear Regression Models for EDSS, Remaining MSQLI variables and MSFC

\begin{tabular}{|c|c|c|c|c|c|c|c|c|c|c|}
\hline Variable & EDSS & FATIGUE & PAIN & SEX & BLADDER & BOWEL & VISUAL & PDQ $S$ & SOCIAL & MSFC \\
\hline Constant & 5.0 & 2.6 & 8.1 & -7.6 & -5.7 & 0.6 & -1.2 & 0.9 & 45.6 & -0.07 \\
\hline Age & & & & & & -0.1 & & -0.1 & & \\
\hline Duration of MS & & & & & & & & & & -0.01 \\
\hline $\operatorname{Sex}(m=1, f=2)$ & & & & & & & & & -6.3 & \\
\hline Clinical course & -1.6 & & & & & & & & & \\
\hline Education & & & -1.9 & & & -1.0 & & -1.2 & & \\
\hline Live with someone & & & & 4.7 & & & & & 16.4 & \\
\hline EDSS numeric value & $\mathrm{n} / \mathrm{a}$ & 0.5 & 0.7 & 0.6 & 0.8 & & & & & -0.1 \\
\hline On disability & .001 & & & & & & & & & \\
\hline Permitted to drive & -0.5 & & & & & & -1.5 & & & 0.6 \\
\hline Currently smoking & & & & & & & 1.4 & & & \\
\hline Intermittent catheterization & & & & & & 3.4 & & & 15.0 & -0.4 \\
\hline Use of aids (1-4) & 0.9 & & & & & & & & & -0.2 \\
\hline Medication for pain & & & 4.0 & & & & & & & \\
\hline Antidepressant use & & & & 3.7 & & & 1.1 & & & \\
\hline Migraines & & & & & & & 0.9 & 2.0 & & 0.2 \\
\hline Clinical depression & & 1.9 & 3.4 & & & & & 3.0 & -15.2 & \\
\hline Incontinence & & & & & & 1.6 & & & & \\
\hline Caregiver & & 2.0 & & & & & & & 8.8 & \\
\hline Use of Allied Health & & 1.5 & & & & & & 1.3 & & \\
\hline Urology & & & & & 3.9 & & & & & \\
\hline Dietician & & & & 3.4 & & & & & & \\
\hline Visiting nurse & 0.5 & & & & & & 1.2 & 1.8 & & \\
\hline Homemaker services & & & & & 2.4 & 2.7 & & & & \\
\hline Support group & & & & & & & & 1.9 & & \\
\hline F-statistic & 140.2 & 21.6 & 20.7 & 6.9 & 38.5 & 17.2 & 14.3 & 11.8 & 13.3 & 57.7 \\
\hline p-value of model & $<0.001$ & $<0.001$ & $<0.001$ & $<0.001$ & $<0.001$ & $<0.001$ & $<0.001$ & $<0.001$ & $<0.001$ & $<0.001$ \\
\hline Adjusted R-square & 0.71 & 0.23 & 0.23 & 0.10 & 0.30 & 0.26 & 0.20 & 0.22 & 0.19 & 0.64 \\
\hline
\end{tabular}

For dichotomous variables, no=1, yes $=2$. For clinical course, $1=$ progressive, $2=$ relapsing. All variables listed were statistically significant $(\mathrm{p}<0.05$ minimum). Higher scores represent poorer function for all but Social and MSFC. EDSS = Expanded Disability Status Scale; PDQ=Perceived Deficits Questionnaire; MSFC = Multiple Sclerosis Functional Composite 
PDQ and social function) and antidepressant use (2 models including sexual function and visual function). Higher education was associated with better outcomes in three models (pain, bowel function and the PDQ), as was the ability to drive an automobile (EDSS, visual function and the MSFC). Age was associated with better bowel function and fewer perceived deficits. The remaining variables were associated with two or fewer outcomes.

\section{Discussion}

The goal of the baseline component of the study was the measurement of both generic and condition-specific aspects of HRQOL, as well as the identification of factors associated with these outcomes. The baseline assessment indicates that there is a substantial burden of illness associated with MS, with all differences between the study population SF-36 scores and the age- and sex-adjusted normative data $^{21}$ attaining statistical significance. This was more pronounced in physically oriented than in mentally-oriented domains, which has been noted by others. ${ }^{4,7,12}$ However, our findings do not support those of a population-based US study, which found that most HRQOL domains were similar for the MS cohort and the general US population. ${ }^{7}$ Rather, our findings are similar to those of an Italian study, which found that all SF-36 domains were significantly and negatively affected by MS. ${ }^{9}$ Differences in the patient population may have been a factor here, as both our sample and the Italian sample had a higher median EDSS (3.5 and 4.0 as compared to 3.0 for the $\mathrm{US}^{7}$ ), and the US sample had a higher percentage of relapsing remitting patients $(65 \%)^{7}$ than our sample $(56 \%)$.

In the regression analyses, a self-reported history of clinical depression was represented the most frequently, appearing in 10 of the 20 models (listed in the results), particularly in mentallyoriented domains. Only $18.3 \%$ of the sample reported depression, but it has a consistent, negative association with HRQOL. This is consistent with other research, which has also identified a strong link between depression and HRQOL, , , 22,23 and suggests that identification and treatment of depression in those with MS may improve their quality of life. ${ }^{22}$

Education and income were the only two consistently positive predictors of HRQOL. The positive association between higher socioeconomic status and HRQOL has been noted in other research, ${ }^{5,24-26}$ as has the negative impact of unemployment, lost income, economic pressure and disability. ${ }^{5,6,24-26}$ Consistent with these findings, being on disability was negatively associated with two outcomes (SF-36 general health perceptions and the EDSS), while unemployment was also negatively associated with general health perceptions.

Level of disability, as characterized by the EDSS, was also strongly and negatively associated with HRQOL, appearing in six models. However, it only appeared in the physical function domain of the SF-36, as noted by others, ${ }^{5,7}$ and was much more highly associated with the condition-specific measures, appearing in the models of fatigue, pain, sexual satisfaction, bladder control and the MS functional composite. Use of aids appeared in four models, including both the SF-36 physical function and PCS score, as well as the EDSS (as one would expect, given that it is part of the definition of EDSS) and the MSFC. A clinical course of progressive versus relapsing remitting was not strongly associated with the outcomes, appearing only in the models of EDSS and the SF-36 role physical, and favouring the relapsing remitting group. This has been noted in one other study. ${ }^{7}$

Age had a mixed effect, appearing in five models but having a positive association in three and a negative association in two. It was associated with a poorer SF-36 physical function and PCS score, but was associated with better mental health, bowel function and perceived deficits. The physical findings may reflect a general trend towards poorer HRQOL associated with aging, which has been demonstrated in MS, in other diseases and in a normative population. ${ }^{12,21}$ The stability and even improvement in mental health despite significant disability has also been noted previously, ${ }^{4,12}$ and may reflect patient adaptation to the disease and effective supportive care.

Previous research which found that men did somewhat more poorly than women ${ }^{5,14,27}$ received weak support in this study, and only in the social function domain of the SF-36. Family history, which has also been identified as negatively associated with HRQOL in MS, ${ }^{5}$ did not appear in any of the models.

A variety of support services and interventions were consistently associated with poorer HRQOL. One or more of the use of a caregiver, homemaker services, visiting nurse, allied health, urology, counselling, dietician and use of a naturopath/other alternative care professional were represented in 16 of 20 models. Only the SF-36 role emotional domain, the MCS, the pain effects scale and the MSFC did not have at least one of these in their models. This does not imply that these measures do not enhance quality of life; a more probable explanation is that those with poorer function and HRQOL are more likely to use these services. Only one of these variables, the use of an informal caregiver, was positively associated with one scale, the modified social support survey.

The variables associated with the SF-36 domains tended to be similar to those associated with the condition-specific components of the MSQLI, suggesting that there may be some overlap in the concepts measured by the questions. In fact, correlation between the 20 outcomes within this baseline assessment was high, with the majority of the correlations attaining statistical significance. This suggests that the condition-specific measures may not provide a great deal of additional information. Use of the MSFC and in particular the PASAT created a challenge, with $5 \%$ of the sample refusing to do it and $8 \%$ refusing to finish it once they had started it. However, an assessment of the PDQ as an alternative to the PASAT indicated that it was not a promising measure of functional deficits, ${ }^{19}$ and the MSQLI questionnaires were generally well received and could be completed at the respondents' leisure. Existing evidence suggests that a combination of generic, condition-specific and functional measures may provide the best information with regard to understanding the diverse symptoms of MS, and their impact on patient quality of life. ${ }^{4,5,15}$ It may be necessary to find the balance between optimizing the information obtained, and minimizing respondent fatigue.

There are several limitations to this study. First, the large number of analyses undertaken may have resulted in some associations attaining statistical significance by chance alone. For this reason, the results must be interpreted within a clinical context and assessed in relation to clinical relevance. Second, with the exception of three outcomes (SF-36 physical function, 
EDSS and the MSFC), the percentage of variation accounted for by these models tended to be modest, with some as low as $17 \%$ (bodily pain), 14\% (vitality) and 10\% (sexual satisfaction), although sample size may have been a factor for sexual function, as the analysis was based on a subset of those who had a relationship with a primary partner. However, this does suggest that many of the factors associated with HRQOL may be beyond the scope of the typical assessment of MS patients, even when augmented by additional sociodemographic information (e.g. economic circumstances, spiritual beliefs, psychological adjustment and coping strategies). ${ }^{12}$

Despite these limitations, this study provides valuable insight into the HRQOL of those with MS. The sample size was larger than most studies of HRQOL in this population, and the outcomes included both generic and condition-specific measures of HRQOL. Moreover, although the study was clinic-based, the findings can be considered to be generally representative of the Canadian MS population. ${ }^{1}$ This is based on the finding of a previous study using clinic-based MS patients across Canada, which noted that over $80 \%$ of MS patients attend an MS clinic, and that patients from a number of centres (including Kingston) were representative of the national MS population. ${ }^{1}$

It is clear that there is a substantial burden of illness associated with MS when compared to the general population. In addition, the assessment of HRQOL provides insight into patient function and well-being beyond that which can be obtained by physical assessment alone, and will provide a basis for future research aimed at improving the management of MS patients. ${ }^{4}$ Subsequent research within this Kingston sample will examine change in HRQOL over two years, as well as the factors associated with change.

\section{ACKNOWLEDGEMENTS}

Funding for this study was provided by the Multiple Sclerosis Society of Canada. The authors thank all of those who participated in this study.

\section{REFERENCES}

1. The Canadian Burden of Illness Study Group. Burden of illness in multiple sclerosis: Part I: Cost of illness. Can J Neuro Sci. 1998;25:23-30.

2. Patwardhan MB, Matchar DB, Samsa GP, McCrory DC, Williams RG, Li TT. Cost of multiple sclerosis by level of disability: a review of literature. Mult Scler. 2005;11:232-9.

3. Grima DT, Torrance GW, Francis G, Rice G, Rosner AJ, Lafortune L. Cost and health-related quality of life consequences of multiple sclerosis. Mult Scler. 2000;6:91-8.

4. The Canadian Burden of Illness Study Group. Burden of illness in multiple sclerosis: Part II: Quality of Life. Can J Neuro Sci. 1998;25:31-38

5. Brunet DG, Hopman WM, Singer MA, Edgar CM, MacKenzie TA. Measurement of health-related quality of life in multiple sclerosis patients. Can J Neuro Sci. 1996;23:99-103.

6. Aronson KJ. Quality of life among persons with multiple sclerosis and their caregivers. Neurology. 1997;48:74-80.

7. Pittock SJ, Mayr WT, McClelland RL, Jorgensen NW, Weigand SD, Noseworthy $\mathrm{JH}$, et al. Quality of life is favorable for most patients with multiple sclerosis: a population-based cohort study. Arch Neurol. 2004;61:679-86.

8. Kurtzke JF. Rating neurological impairment in multiple sclerosis: an expanded disability status scale (EDSS). Neurology, 1988;33:1444-52.
9. Patti F, Cacopardo M, Palermo F, Ciancio MR, Lopes R, Restivo D, et al. Health-related quality of life and depression in an Italian sample of multiple sclerosis patients, J Neurol Sci. 2003;211:5562.

10. Ware JE Jr, Snow KK, Kosinski M. SF-36 health survey: manual \& interpretation guide. Boston, Massachusetts: The Health Institute, New England Medical Center; 1993.

11. Ware JE, Kosinski M, Keller SD. SF-36 physical and mental health summary scales: a user manual and interpretation guide. Boston MA Health Institute; 1994.

12. Singer MA, Hopman WM, MacKenzie TA. Psychological adjustment in four chronic medical conditions. Qual Life Res. 1999; 8:687-91

13. Ritvo PG, Fischer JS, Miller DM, Andrews H, Paty DW, LaRocca NG. Multiple sclerosis quality of life inventory: a user's manual. New York: National Multiple Sclerosis Society; 1997.

14. Hopman WM, Coo H, Brunet DG, Edgar CM, Singer MA. Longitudinal assessment of health-related quality of life (HRQOL) of patients with multiple sclerosis. International J MS Care. 2000;2:15-26.

15. Vickrey BG, Hays RD, Genovese BJ, Myers LW, Ellison GW. Comparison of a generic to disease-targeted health-related quality-of-life measure for multiple sclerosis. J Clin Epid. 1997; 50:557-69.

16. Miller DM, Rudick RA, Cutter G, Baier M, Fischer JS. Clinical significance of the multiple sclerosis functional composite: relationship to patient-reported quality of life. Arch Neurol. 2000;57:1319-24.

17. Sullivan JJL, Edgeley K, Dehoux E. A survey of multiple sclerosis. Part 1: perceived cognitive problems and compensatory strategy use. Can J Rehab. 1990;4:99-105.

18. Fischer JS, Rudick RA, Cutter GR, Reingold SC. The Multiple Sclerosis Functional Composite measure (MSFC): an integrated approach to MS clinical outcome assessment. Mult Scler. 1999; 5:244-50.

19. Coo H, Hopman WM, Edgar CM, McBride EV, Brunet DG. The paced auditory serial addition test: to what extent is it performed as instructed, and is it associated with disease course? Mult Scler. 2005; 11:85-9.

20. Fischer JS, Jak AJ, Knicker JE, Rudick RA, Cutter G. Administration and scoring manual for the Multiple Sclerosis Functional Composite Measure. New York, New York: National Multiple Sclerosis Society; Revised 2001.

21. Hopman WM, Towheed T, Anastassiades T, Tenenhouse A, Poliquin S, Berger C, et al. Canadian normative data for the SF-36 health survey. CMAJ. 2000; 163:265-71.

22. Janardhan V, Nakshi R. Quality of life in patients with multiple sclerosis: the impact of fatigue and depression. J Neurol Sci. 2002;15:51-8.

23. Lobentanz IS, Asenbaum S, Vass K, Sauter C, Klosch G, Kollegger $\mathrm{H}$, et al. Factors influencing quality of life in multiple sclerosis patients: disability, depressive mood, fatigue and sleep quality. Acta Neurol Scand. 2004;110:6-13.

24. McCabew MP, De Judicibus M. The effects of economic disadvantage on psychological well-being and quality of life among people with multiple sclerosis. J Health Psyc. 2005; 10:163-73.

25. Williams RM, Turner AP, Hatzakis M Jr, Bowen JD, Rodriques AA, Hasselkorn JK. Prevalence and correlates of depression among veterans with multiple sclerosis. Neurology. 2005;64:75-80.

26. Jiang Y, Hesser JE. Associations between health-related quality of life and demographics and health risks. Results from Rhode Island's 2002 Behavioural Risk Factor Survey. Health Qual Life Outcomes. 2006;3:14 (Epub ahead of print).

27. Miller A, Dishon S. Health-related quality of life in Multiple Sclerosis: the impact of disability, gender and employment status. Qual Life Res. 2006;15:259-71. 